\title{
Corpo e Embelezamento: a Criança Participante de Concurso de Beleza
}

Body and Beautification: the Child Participating in Beauty Pageant

Cuerpo y Embellecimiento: los Niños Participantes em Concursos de Beleza

Isis Alves de Carvalho \& Monise Gomes Serpa

Universidade Federal do Rio Grande do Sul

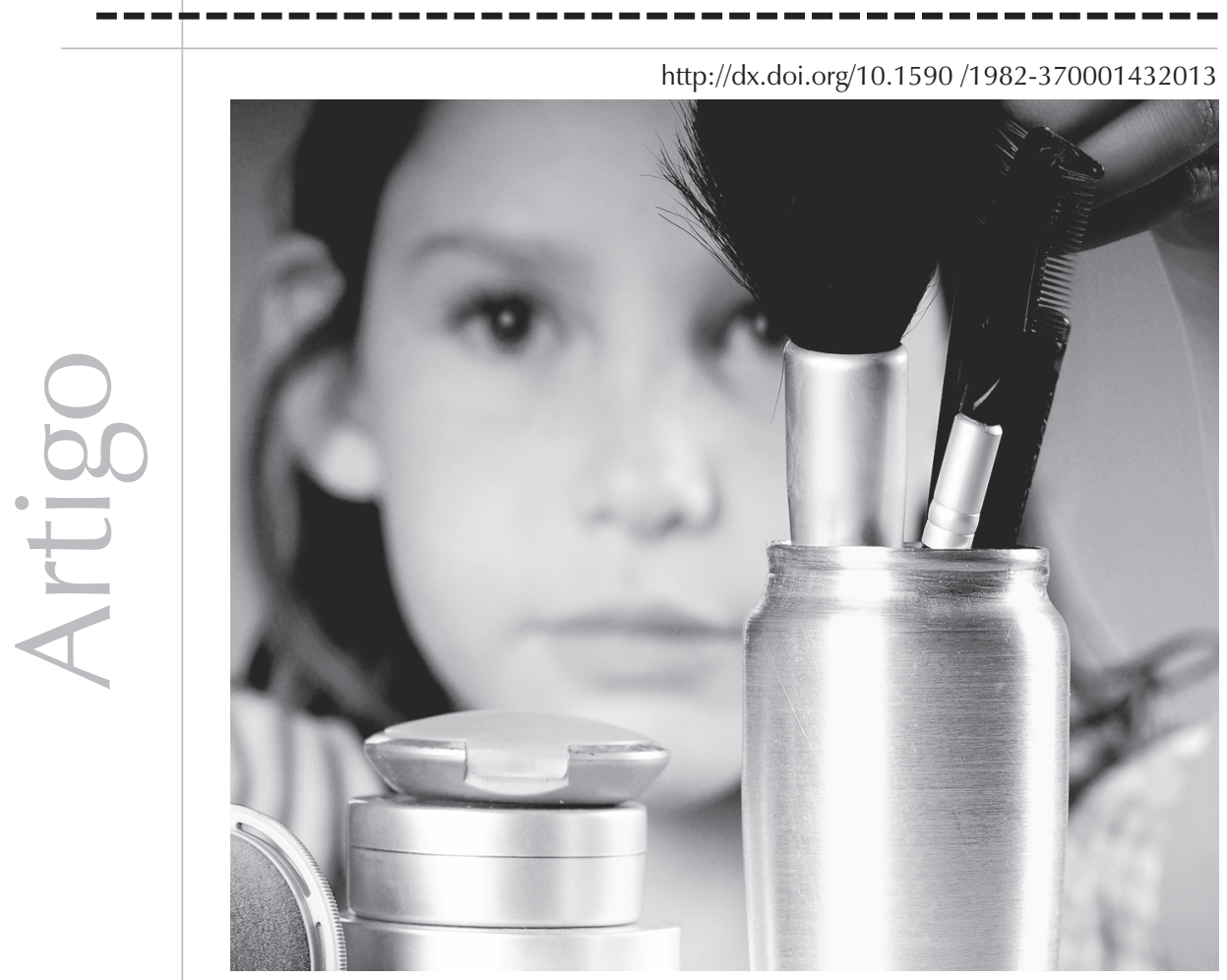


Resumo: Este trabalho tem como objetivo analisar as concepções de uma mãe sobre a participação de sua filha nos concursos de beleza infantil, com vistas a compreender como estão imbricadas as percepções sobre o corpo feminino, as lógicas de embelezamento e a sua relação com os discursos midiáticos. Realizou-se um estudo de caso com entrevista de roteiro semiestruturado, abordando questões sobre corpo, embelezamento e mídia. A entrevistada tem 32 anos e sua filha tem 9, a qual ingressou nas passarelas com 2 anos e meio. Os resultados apontaram que as implicações dos discursos midiáticos estabelecem valores, agindo como mirantes de um ideal corporal a ser atendido, favorecendo a constituição da "adultalização" precoce, além de contribuir para a formação de criança consumidora em uma sociedade espetacularizada. Faz-se necessário refletir sobre a infância na contemporaneidade, principalmente de meninas, e de que forma ela tem sido instigada a produzir seus corpos diante dos preceitos mercadológicos de embelezamento.

Palavras-chave: Corpo. Embelezamento. Comportamento do consumidor. Meios de comunicação.

Abstract: This paper aims at analyzing the mother's conceptions on her daughter participation in infantile beauty pageant in order to understand how the perceptions on female body, the rationale of beautification, and its relationship with media discourses are imbricated. A case study was undertaken in a semi-structured interview approaching issues about the body, beautification, and the media. The interviewee is a $32 \mathrm{yrs}$ old mother, her daughter is $9 \mathrm{yrs}$ old who started in walkways at age of two and half years old. The results showed that implications from media discourses set values, acting as belvederes of a body ideal to be met, favoring the set up of precocious "adulthood", in addition to contributing to raising a consumerist child in a spectacularized society. It becomes necessary to reflect on childhood in current days, particularly on girls, and in what ways it has been incited to produce their bodies in view of marketing precepts of beautification.

Keywords: Body. Beautification. Consumer behavior. Communication Media.

Resumen: Este trabajo tiene como objetivo analizar las concepciones de una madre sobre la participación de su hija en los concursos de belleza infantil, con vistas a comprender cómo están relacionadas las percepciones sobre el cuerpo femenino, las lógicas de embellecimiento y su relación con los discursos mediáticos. Se realizó un estudio de caso con entrevista de guión semiestructurado, abordando cuestiones sobre cuerpo, embellecimiento y medios. La entrevistada tiene 32 años, su hija 9 que empezó en las pasarelas con 2 años y medio. Los resultados apuntaron que las implicaciones de los discursos mediáticos establecen valores, actuando como miradores de un ideal corporal a ser atendido, favoreciendo la constitución de la "adultización" precoz, además de contribuir para la formación de niños consumidores en una sociedad espectacularizada. Se torna necesario reflexionar sobre la infancia en la contemporaneidad, principalmente de niñas, y de qué forma ella ha sido instigada a producir sus cuerpos delante de los preceptos mercadológicos de embellecimiento.

Palabras-clave: Cuerpo. Embellecimiento. Conducta del cosumidor. Medios de comunicación. 
O conceito de infância passou por um longo processo de construção e elaboração, partindo de inúmeras teorias dos diferentes campos do conhecimento. Várias concepções foram se delineando na área médica, psicológica, jurídica, pedagógica, antropológica e sociológica, de maneira que, atualmente, não podemos classificar o conceito de infância como estável, "natural" e homogêneo (Neckel \& Guizzo, 2003). Assim, podemos falar que existem inúmeras infâncias em constantes processos de ressignificação e transformação, que variam conforme o tempo, classe social, gênero e cultura em que as crianças estão inseridas (Neckel \& Guizzo, 2003).

A maquiagem carregada, os vestidos briIhantes, o laquê nos cabelos, a pele bronzeadíssima e depilada, os cílios postiços, tudo isso, acompanhado da pressão de ser a mais bela e talentosa, pode ser visto nas crianças participantes dos concursos de beleza infantil. Nas competições, o que se percebe são garotinhas utilizando trajes de banho e desfilando como se fossem mulheres adultas, sem apresentar qualquer traço da idade que realmente possuem, deixando a imagem de pureza, ingenuidade e inocência da criança para trás.

Baseando-se nesta crescente valorização do embelezamento, que atinge também as crianças, somos instados a pensar a questão abordada pelo filme americano Pequena Miss Sunshine. A análise do filme é feita por Guizzo (2010), lembrando-nos que o filme ilustra, de forma descontraída e bem humorada, a questão do consumo de imagens e estereótipos de padrões de beleza na infância e a preocupação excessiva que atinge pequenas meninas com sonhos de ser top models conhecidas e bem-sucedidas. No filme, estamos intimamente imbricados com problemas relacionados ao convite à exposição do corpo de crianças, à incitação e à manifestação de uma sensualidade precoce.
De modo geral, observa-se que em um país como o Brasil a situação se repete: crianças são aplaudidas candidamente por adultos orgulhosos das artes, por vezes pornográficas, de corpos que na infância iniciam uma experimentação lúdica de si mesmas (Fischer, 2008).

A preocupação com a beleza, que atinge especialmente meninas e mulheres, não é entendida como algo natural e inerente aos sujeitos femininos, mas sim como parte de um sistema histórico, social e cultural estabelecido e programado pelas instâncias culturais, visuais e sociais (Guizzo, 2010). O corpo é elevado ao estatuto de "artefato cultural" devido à coação a que é submetido pela cultura, sendo ele apropriado, domesticado e alterado, conforme as crenças e ideias coletivas expressadas pela sociedade (Queiróz \& Otta, 2000).

Na lógica do embelezamento infantil, estão impregnados artefatos que, por sua vez, constituem as pedagogias culturais. Essas novas formas infantis de existir são, em grande parte, determinadas pela televisão, mas não exclusivamente por ela. Os meios de comunicação também exercem uma forma de pedagogia cultural, na medida em que compartilham com a escola e a família a função de fornecer às crianças informações e valores constituintes de sua subjetividade (Steinberg \& Kincheloe, 2001). Conforme Goellner (2003), existem várias pedagogias em circulação na sociedade, sejam os filmes, músicas, revistas, livros, imagens e propagandas que estão a dizer de nós, pelo que exibem ou pelo que ocultam. Além de dizer de nossos corpos e, por vezes, de forma tão sutil que nem mesmo percebemos o quanto somos capturadas(os) e produzidas(os) pelo que lá se articula. Nesse sentido, "música popular, televisão, cinema, vídeo e jogos de computador criam novos ídolos, aspirações e artefatos que influenciam profundamente 
o pensamento e a conduta da juventude contemporânea" (Kellner, 2001, p. 135).

Assim, não como fator isolado, mas inserido no contexto das diversas transformações sociais nas últimas décadas, a sempre crescente intervenção dos meios de comunicação na vida das sociedades e dos indivíduos conduz ao surgimento de uma nova configuração de infância, desenhada a partir de sua inserção na lógica fundamental das sociedades capitalistas - a do consumo. A criança é inserida na economia, seja como um produto, ao vender sua mão de obra, seja como consumidora, ao realizar a compra de um bem ou serviço (Neckel, Guizo, 2003).

Diante dessas observações, busca-se entender, por meio do discurso da mãe entrevistada, como a criança participante de concursos de beleza infantil é envolvida pelas pedagogias culturais, uma vez que as lógicas de embelezamento infantil fazem parte de um processo no qual atribui significados sociais aos corpos a partir dos artefatos culturais construídos socialmente. Tal reflexão concerne não apenas aos profissionais que atuam no campo da Psicologia, como também a todos os interessados em pensar sobre o papel fundamental que as tecnologias da informação desempenham nas sociedades pós-modernas. Lembra-se, também, que a gama de possibilidades de identidades assumidas hoje pela criança, veiculadas especialmente pela mídia, decorre da atual condição da sociedade em que ela cresce e se desenvolve, constituindo, em última instância, um rico instrumento de conhecimento dessa sociedade.

\section{Método}

\section{Delineamento}

Esta pesquisa possui uma abordagem qualitativa que, conforme Minayo (2007), diz respeito ao estudo que responde a questões particulares, sendo que o nível de realidade a ser estudado não pode ou não deve ser quantitativo. Este artigo tem cunho exploratório e, como define Gil (2009), tem como objetivo proporcionar maior familiaridade com o problema, com vista a torná-lo mais explícito ou a constituir hipóteses. Foi realizado um estudo de caso que, segundo Yin (2005), tal procedimento é preferível quando o(a) pesquisador(a) tem pouco controle sobre os acontecimentos e quando o foco se encontra em fenômenos contemporâneos inseridos em algum contexto da vida real.

\section{Participante}

Esta pesquisa teve como participante uma mãe de criança vencedora de concursos de beleza. A participante, identificada como A1, tem 32 anos e sua filha, com 9 anos, ingressou com 2 anos e 6 meses nas passarelas.

\section{Instrumentos e procedimentos}

O projeto, inicialmente, passou por uma banca virtual, para, em seguida, ser submetido ao Comitê de Ética da Unifra, sob o registro do CEP no 345.2011.3 e seguiu as resoluções no 196/96 do Ministério da Saúde (Brasil, 1996), que dispõe sobre a pesquisa com seres humanos, e no 016/2000 do Conselho Federal de Psicologia (CNP, 2000). Aprovado o projeto, a pesquisadora entrou em contato com uma pessoa de referência no tema da pesquisa, a qual indicou a participante A1. O primeiro contato foi por meio do telefone e, após, realizou-se o agendamento da entrevista. Foi realizado um encontro com duração de duas horas, em um espaço da escola de sua filha, escolhido pela própria participante. Foi utilizada uma entrevista com roteiro semiestruturado, abordando questões que remetem ao corpo, ao embelezamento e, por fim, à mídia. Nesse encontro, foram explicitados os objetivos da pesquisa, sendo lidos e entregues os Termos de Consentimento Livre e Esclarecido (TCLE). A entrevista foi gravada e transcrita para análise do seu conteúdo. 


\section{Análise dos dados}

Para análise das informações coletadas, foi utilizado o método de Análise de Conteúdo tipo temático proposto por Minayo (1996), como sendo aquele que possibilita a confirmação ou não das hipóteses estabelecidas, assim como nos permite descobrir o que está por trás dos conteúdos manifestos no discurso. Concluída a análise dos dados, foram criadas três categorias de análise, nas quais foi contemplada a fala da participante acerca do tema da pesquisa: "A Gisele Bündchen é ícone de beleza e elas sabem. Essas guriazinhas sabem": a mídia e os concursos de Beleza; "Hoje tu vais fazer um comercial da grife 'tal', então tá aqui a grife": a imagem infantil na cultura do consumo e do espetáculo e "Ela sempre toma luftal, que é a dimeticona, para gases, porque ela não gosta de ficar com a barriga dura, estufada": A tirania da beleza na infância e a colonização do corpo.

\section{Resultados e Discussão}

\section{"A Gisele Bündchen é ícone de beleza e elas sabem. Essas guriazinhas sabem": a mídia e os concursos de Beleza}

Esta categoria levará ao debate sobre o que está sendo produzido para a infância na atualidade, bem como sobre o modo como a criança participante de Concurso de Beleza se apropria de tais produtos, mediante discursos que conduzem a uma percepção de corpo, gênero e sexualidade. Da mesma forma, irá problematizar a relação entre a mídia e a ação pedagógica em que diversas vezes somos interpelados(as) e constituídos(as) pelo currículo cultural das mídias e das distintas manifestações presentes no âmbito social.

É interessante acionar reflexões a respeito do empenho da mídia na veiculação dos modelos de corpos e estratégias para a sua construção, sobretudo no que se refere ao feminino. Esse discurso é veiculado em todos os momentos: nas revistas, nos jornais, na televisão, sendo o público leitor ou telespectador assediado continuamente pelos modelos de beleza, na forma, por vezes, de top-models (Borges, 2007), como é citado na fala da participante:

"A Gisele Bündchen é ícone de beleza e elas sabem. Essas guriazinhas sabem!... uma Alessandra Ambrósio.... Normalmente quem desfila, como a S.A, está sempre pesquisando na Internet. Ela vai muito nos desfiles das Angels, no desfile de São Paulo, no Donna Fashion Week, Donna Fashion Iguatemi... elas procuram essas e acabam tendo como referência. Alessandra Ambrósio, Gisele Bündchen, Natália Guimarães..." (A1)

Nesse sentido, Fischer (2003, p. 48) aponta que os imperativos de beleza perseguemnos quase como "tortura", uma vez que os corpos de tantos(as) outros(as) são oferecidos como modelos, operando de forma que transformemos o nosso corpo para atingir esse modelo que tem como características ser belos(as), magros(as), atletas, saudáveis e eternos. Essa ideia é reafirmada por meio da fala da participante:

"Bah! Vejo um futuro brilhante para ela em todos os aspectos, porque eu penso assim: magra... alta... já tem uns pontos para ser modelo!" (A1)

A mídia disponibiliza imagens, figuras e mensagens com as quais o público pode se identificar e imitar, pela beleza inquestionável e pela sua capacidade de produzir verdade, as quais irão exercer "efeitos socializantes e culturais" (Kellner, 2001). Essa consideração vem ao encontro dos seguintes discursos da participante:

“(...)existe um mundo antes da S.A e após a S.A, porque as mães se espelham, acreditam, veem que aquilo é possível. Toda a mãe quer que uma filha seja, não digo que seja Miss, mas que seja modelo, que seja atriz, que tenha seus quinze minutos de fama, como a gente brinca. Então eu 
brinco que a S.A é a Marta Rocha Infantil, que foi eternizada. (...)Eu vejo a S.A como um espelho para muita criança. As mães perguntam qual a roupa que ela veste, de qual loja, onde ela compra calçado, enfim, muita coisa as mães me perguntam através das redes sociais para fazer com que as fiIhas sigam o mesmo caminho." (A.1)

Os personagens da mídia são modelos que inspiram o comportamento juvenil pelas atitudes, linguajar, expressões, características, vestuários e estilos musicais. Pensar as identidades a partir desses referenciais é pensálas como plurais, em constante processo de transformação (Kellner, 2001), como mostra a fala da participante:

“(...é tudo muito itinerante, muito rápido! Muda! Por exemplo: essa moda Restart, que são estas coisas coloridas, ela tem! Ela tem as calças coloridas, as camisas coloridas, xadrez (...) ela gosta dessa moda. (...)Eu acho que tem sim, tem sim um pouco dessa influência da mídia." (A1)

A mídia produz efeitos diretos sobre a vida do seu púbico-alvo, manipulando ou facilitando a construção de identidades (Kellner, 2001). Para a autora, personagens vitoriosos e famosos tornam-se imagens poderosas e ressonantes que são usadas para produzir sentido, identidades, discurso e comportamento, como pode ser visto a seguir:

“(...)Ela lança a moda dela, dita a moda dela e 'siga-me os bons'. A S.A é considerada pela mídia bem 'fashion Miss'. Ela gosta de coisas bem diferentes, de customizar coisas." (A1)

Trata-se de imagens que chegam como imperativos de ideais a serem seguidos, que se transformam em modelos de identificação, constituintes da identidade fabricada pela propaganda. Frente a esta cultura contemporânea, em um panorama marcado pela onipresença da mídia, estamos presenciando um processo permanente de regulação de significados, valores e gostos, sendo todos, em especial as crianças, sujeitas a processos educativos ditados pelos meios de comunicação. Trata-se de considerar a mídia e a cultura por ela produzida como uma das instâncias sociais centralmente implicadas na produção de identidades sociais e subjetividades em nosso tempo. A partir da análise das relações saber/poder que circulam na sociedade, engendradas pela mídia, as crianças participantes de concursos de beleza passam a se tornar "modelos" de corpo, gênero e sexualidade, exercendo um trabalho minucioso de influência sobre as demais crianças que também anseiam por este "ideal".

\section{"Hoje tu vais fazer um comercial da grife 'tal', então tá aqui a grife": a imagem infantil na cultura do consumo e do espetáculo}

Esta categoria irá abordar a criança enquanto ávida consumidora. O segmento do mercado globalizado investiu a criança de um novo poder como cliente, sendo dirigida a ela toda uma série de produtos que as oblitera. Além disso, será levantada uma reflexão a respeito da relação que se estabelece entre corpo, mercadoria e meios de comunicação, ao passo que se configura uma nova sociedade a partir da lógica mercadológica e consumista, em uma dimensão de espetáculo.

Na sociedade contemporânea, o corpo ocupa um lugar central e na mídia, torna-se explicitamente um "corpo-espetáculo". A noção de espetáculo remete à natureza das representações de corpo na contemporaneidade, uma vez que se impõe como a afirmação de toda a vida humana como simples aparência. "O espetáculo apresenta-se como algo grandioso, positivo, indiscutível e inacessível" (Débord, 1997, p. 10) e o mundo vivido passa a ser representado por imagens que tomam o lugar de real, cuja noção revela-se em "o que aparece é bom, o que é bom aparece" (Débord, 1997, p. 16). Assim, como 
principal produção da vida atual, o espetáculo "não deseja chegar a nada que não seja ele mesmo" (Débord, 1997, p. 17). O discurso a seguir corrobora o destaque do autor:

“(...) mas até me provarem o contrário, a S.A. realmente era a mais bonita, tanto que, à medida que as outras meninas foram sendo desclassificadas, as mães das meninas estavam torcendo pela S.A." (A1)

Essa construção se articula fortemente com o consumo, uma vez que, propaga-se, então, a concepção de corpo-mercadoria que se volta especialmente para a venda de imagens corporais de sucesso (Débord, 1997). Não é mais apenas o corpo que interessa ao capitalismo, mas a imagem e a mercadoria desse corpo. Logo, o capitalismo, na busca da ampliação de novos mercados, encontra nas imagens uma vendável mercadoria (Débord, 1997). O corpo enquanto mercadoria pode ser ilustrado pela fala da participante:

“(...) Ah! Hoje tu vais fazer um comercial da grife "tal", então tá aqui a grife! Eu mostro, procuro a coleção passada, pesquiso no "site", pesquiso onde é a fábrica, mostro tudo para ela." (A1)

A vida cotidiana parece haver se transformado em um pseudoglamouroso mundo chamado "espetáculo" (Débord, 1997), no qual a sociedade adere religiosamente à lógica do consumo, hipnotizada pelo fetiche da mercadoria. "O espetáculo é o momento em que a mercadoria ocupou totalmente a vida social" (Débord, 1997, p. 30). Valores, pessoas, tempo, cultura, religião, espaço, história, quase nada escapa à ideologia dinheirista avassaladora da comercialização, substituindo o verdadeiro pelo falso, o real pela ilusão, o original pela cópia. É assim que, em uma economia mercantil-espetacular, a produção alienada vem juntar-se ao consumo alienado (Débord, 1997).

Nesta questão da ressignificação da imagem dos infantis, Neckel (2006) também associa essa lógica às vias do consumo. O mercado, por meio das grandes empresas, investe na imagem e na adoração da figura infantil, na busca incessante de novos nichos de consumo (Neckel, 2006). As crianças se tornaram ávidas consumidoras, além de serem objetos de consumo. Esse mecanismo do mercado acontece de maneira intensa por meio da publicidade. Ela passa a veicular qualquer motivo ou imagem que possa estimular o consumo, não somente para vender, mas também incentivando, de maneira sedutora, a compra de produtos como uma grande novidade, mesmo que nada tenham de novo (Neckel, 2005). Steinberg e Kincheloe tematizam a questão das propagandas voltadas para o universo infantil: "corporações que fazem propaganda de toda a parafernália para crianças consumirem promovem uma teologia de consumo que efetivamente promete redenção e felicidade através do ato de consumo" (Steinberg \& Kincheloe, 2001, p. 24).

É interessante analisar, a partir deste "império de consumo" contemporâneo, como se dão as novas concepções de infância produzidas nas e pelas relações de consumo, por meio das pedagogias culturais. A escola não é mais o único espaço de aprendizado dos valores e significados culturais (Neckel, 2006). Isso significa apontar que se a Pedagogia teve de inventar uma criança e uma infância para o projeto moderno civilizador, certamente, as instâncias midiáticas reinventam uma criança para o consumo de seus produtos. As crianças não aparecem mais como inocentes e, principalmente, imaturas. As meninas aparecem como pequenas mulheres provocantes, preocupadas com seus corpos, desfilando, fazendo poses demonstrando que sabem bem o que querem no momento das compras (Neckel, 2005; Steinberg \& Kincheloe, 2001; Walkerdine, 1999). Isso se confirma pelo seguinte discurso: 
"Como a S.A. participou de diversos eventos e sempre foi impecável em suas aparições, ela mesma está acostumada a dizer o que e como gosta de se produzir." (A1)

Há disposição de vender determinada ideia ou produto, produzindo uma Pedagogia que narra o sujeito como independente e livre para escolher, mas que opera com mecanismos de (auto)controle e de (auto)regulação, normatizando as relações sociais e materializando-as por meio das imagens (Sabat, 2001). Nesse sentido, percebe-se que há uma Pedagogia, um determinado tipo de currículo que opera por meio de uma lista de procedimentos e técnicas voltadas para produzir e reproduzir tipos específicos de comportamentos, valores, hábitos e atitudes pessoais diretamente conectados com o tipo de sociedade na qual estão inseridos. A mídia é o próprio espetáculo que acontece por meio de dispositivos disciplinares ocultos, conforme o panoptismo de Foucault (2004), no qual o indivíduo prisioneiro é vigiado sem desejar, mas se sente seguro com esse modelo de vigilância total e absoluta. Estamos mais subjetivados que os prisioneiros dos Panópticos, pois, escolhemos, por "vontade própria", ser vigiados e vigiar os outros. Cabe aqui ressaltar que: a criança passa a desejar o que é mostrado como algo bom, ou seja, determinados modos de felicidade se dissipam nos espaços midiáticos e se impõem como modelos a serem seguidos. Consideremos as falas abaixo:

“(...) no ano em que a S.A. participou tinham só seis candidatas e no ano seguinte tinham dezoito (...). Quando teve o resultado final, a S.A ganhou, e quando a gente retornou ao Brasil, a notícia já estava no site da X. No final do dia, era a notícia mais lida e teve o reconhecimento do país inteiro." (A1)

As falas acima mostram, também, a intervenção da mídia de forma exacerbada no que tange às imagens tomadas como modelos para a aparência, agindo como mirantes de um ideal corporal a ser atingido. A noção de beleza exterior se tornou tão importante que marca a atualidade como a sociedade da aparência, dos rostos e corpos belos e esbeltos. Os mecanismos exigidos e tidos como verdadeiros pelo poder disciplinar fazem uso de atributos corporais para controlar a sociedade (Foucault, 2004). Eis a afirmação da entrevistada, quando questionada sobre o modelo de corpo ideal para suas filhas:

"Ah, eu acho que magra, com cintura, com bunda, com peito." (A1)

Debruçando-se, ainda, nesse quesito de espetacularização, Sibilia (2008) enfatiza que a intimidade tem se convertido em uma espécie de cenário no qual devemos montar o espetáculo de nós mesmos: a vitrine da própria personalidade. Com a revolução tecnológica da informação, a proliferação da Internet, o aumento de blogs e sites de relacionamento, o significado de intimidade mudou radicalmente, criando uma vida espetacularizada. Nessa nova perspectiva, a vida e as relações ganham um novo sentido e a pessoa só existe se aparece para alguém (Sibilia, 2008). Uma das principais manifestações dessa virada é um crescente desejo de ser visto, uma vontade de se construir como um eu visível, como um personagem que os outros podem ver e, graças a esse olhar reconfortante, confirmam a existência de quem se exibe. Assim, o homem moderno tem uma personalidade alterdirigida ou orientada para o olhar dos outros. Isso não acontece apenas na Internet, mas nas diversas práticas contemporâneas na quais impera esse desejo desesperado de que os demais nos enxerguem e nos observem para que possamos existir ( $\mathrm{Si}$ bilia, 2008). Esta afirmação vem ao encontro da fala da participante:

"Ela adora, por exemplo, pegar a câmera e o celular dela, se filmar e se assistir! Qualquer coisa que ela está fazendo, pede para ser filmada. Agora ela começou aula de cinema, por exemplo. Youtube! Ela adora acessar o Youtube e ficar assistindo vídeos." (A1) 
Valendo-se da sociedade escópica, típica de nosso tempo, reduz-se o indivíduo a sua imagem, o ser visto, induzido ao "tenha seu minuto de fama". Os avanços tecnológicos atuais permitem a fabricação de múltiplos aparelhos reprodutores de imagens não apenas para que o indivíduo possa se ver, mas principalmente para ser visto, como referido na fala acima.

Na vitrine da mídia, desde cedo, quem tiver construído a melhor imagem terá seu corpo aceito e a sua imagem como modelo a ser consumido. Assim, a aparência e a sua manutenção são categorias que se retroalimentam na lógica do consumo (Borges, 2007). Atente-se para o comentário:

"Ela tem essa preocupação: passar uma basezinha ou colocar uma meia calça... se vai tirar foto, se depois corrige no fotoshop (...)" (A1)

Existe um bombardeio de imagens que insistem em dizer o tempo todo e de forma exagerada que devemos ter corpos belos e isso significa sermos cada vez mais magros e ter um biótipo ideal dentro de um padrão estético propagado no espetáculo imagético das pedagogias culturais. Ainda nessa perspectiva, vale destacar que, fora das instituições educacionais, estão as empresas como organizações produtoras de diversões que saciam nossos desejos, na forma de um processo pedagógico que "captura nossa imaginação e constrói nossa consciência" (Steinberg, 1997, p. 102). O primeiro objetivo dessas organizações empresariais não é o bem-estar das pessoas, mas o lucro auferido pela venda de seus produtos de consumo. Dessa forma, os interesses comerciais ditam a cultura infantil da mídia (Steinberg \& Kincheloe, 2001) e a margem de lucro é mais importante do que o bem-estar da criança.

A informação abaixo nos remete à beleza direcionada para a promoção de marcas e ao faturamento das indústrias, ou seja, beleza mercadológica:
“(...) existem aqueles que contratam a S.A. para estrelar campanhas publicitárias. Outros contratam a presença, mais conhecida como presença VIP de algum evento, ou inauguração de loja, visitas em feiras, ou a chamam para desfilar. Existem também aqueles que fazem permutas de produtos e serviços, ou seja, presenteiam a S.A. com roupas, acessórios, brinquedos, para que ela os utilize em aparições na mídia." (A1)

Como importantes instâncias de socialização, os meios de comunicação privilegiam em seus conteúdos o corpo, transformando-o em manifestações do espetáculo com o intuito de retificação e alienação, tornando-o mercadoria (Débord, 1997). As crianças participantes de concurso de beleza são incorporadas como fatia do mercado de consumo, por meio da adesão e representação do ideal de corpo. Podemos inferir, assim, que a criança desejada pela mídia é aquela proporcionadora do espetáculo que leva ao consumo.

“Ela sempre toma luftal, que é a dimeticona, para gases, porque ela não gosta de ficar com a barriga dura, estufada": A tirania da beleza na infância e a colonização do corpo

Nesta categoria, serão colocados em pauta os investimentos e as práticas de embelezamento corporal da criança participante de concurso de beleza, uma vez que, neste novo cenário, os padrões de beleza vigentes oriundos das infinitas instâncias culturais, visuais e sociais têm o poder de produzir, demarcar, regular e diferenciar corpos. Será apontado também o biopoder aplicado às novas tecnologias utilizadas nas práticas de embelezamento feminino.

O corpo feminino se torna, antes de tudo, "o corpo-para-o-outro, a aparência que deve ter aos olhos de seus semelhantes" (Borges, 2007, p. 95). As imagens que modelam o corpo operam no sentido de condicionar a identidade corporal da criança para mecanismos de ajuste obrigatórios à tríade 
beleza-juventude-saúde (Borges, 2007). A prática do "culto ao corpo" coloca-se como preocupação apoiada em um discurso que ora lança mão da questão estética e ora da preocupação com a saúde. Vale ressaltar a produção de novos corpos por meio da tecnociência, sendo potencializada pelo uso de diferentes produtos e técnicas. Com isso, assegura-se que o corpo ainda está sujeito a distintas hierarquizações, uma vez que, as intervenções que nele operam, ao mesmo tempo em que podem lhe oferecer liberdades, invocam também estratégias de autocontrole e interdição (Goellner, 2003). Portanto, afirma-se que promessa de uma vida mais longa e saudável é acompanhada de inúmeros discursos e representações que autorregulam o indivíduo, tornando-o, muitas vezes, vigia de si próprio (Goellner, 2003). Considerando-se esse enfoque, uma participante destaca alguns cuidados que o corpo infantil requer:

“(...) requer alguns cuidados com a dieta, que deve ser saudável, pois as crianças tendem para os doces e guloseimas, não costumam gostar de saladas e, em geral, não são adeptas de queijos brancos e frutas.(...) Eu acho que ela já está buscando melhorar, porque prefere água ao refrigerante, come fruta, come cereal, come queijo, toma bastante leite de soja, toma leite desnatado." (A1)

Observa-se que as crianças se preocupam com a estética e a possibilidade de moldar o corpo a partir das práticas reguladoras, como a dieta, proporciona a sensação de estar o mais próximo possível de um padrão de beleza hegemônico, globalmente estabelecido. Cuidar do corpo torna-se um imperativo tão poderoso que conduz à ideia de obrigação, cujo fracasso gera um sentimento de culpa (Castro, 2003). Eis o seguinte comentário:

“Uma coisa que ela não gosta é quando está barriguda. Vou ser bem sincera: ela sempre toma luftal, que é a dimeticona, para gases, porque ela não gosta de ficar com a barriga dura, estufada." (A1)
Observa-se a adesão precoce ao cuidado e transformação corporal com o intuito de enquadrar seus corpos nos padrões vigentes de beleza, visto que as representações que circulam atreladas ao belo contribuem para a ideia de que ser gordo(a) e parecer (ou ser) velho(a), entre outras características, são tomados como símbolo da feiura, sinal de falta de força de vontade associada à baixa autoestima (Guizzo, 2010). Aqueles(as) que sequer tentam ser belos são vistos(as) como preguiçosos(as), relaxados(as), relapsos(as) consigo mesmos(as), levando-se em conta também as inúmeras possibilidades que hoje estão disponíveis e auxiliam na construção desse corpo. Em contrapartida, ser magro(a), parecer (ou ser) jovem é geralmente visto como algo desejável e interpretado como sinônimo de felicidade. A busca pela beleza se tornou sinônimo de amor-próprio e a busca de um corpo "perfeito", o principal bem (Guizzo, 2010).

As representações sobre o que é ser belo(a) são, reiteradamente, mostradas na mídia e, desde muito cedo, compreendidas e incorporadas pelas meninas. O comportamento de meninos e meninas tem se valido na tentativa de, cada vez mais, potencializar sua aparência de acordo com os padrões hegemônicos difundidos em propagandas, novelas e anúncios publicitários que dizem como corpos, cabelos, peles, maneiras de se vestir podem ser melhoradas (Guizzo, 2010). Isso é demonstrado na seguinte fala:

“(...) com quatro anos a gente estava de novo no salão de beleza (...)" (A1)

Quando solicitada a descrever o seu entendimento sobre o corpo feminino, a entrevistada responde:

"Eu acho que o corpo feminino... tem que saber lidar com a tua realidade. 'É alta? É magra? É baixa? É gorda? Tem celulite? Não tem?'. 'O que tu podes fazer?'. Tu podes fazer alguma coisa para melhorar a tua realidade." (A1) 
Entende-se que o corpo é então visto como algo a ser permanentemente construído, manipulado, tornando-se objeto de diferentes intervenções. Tais ações visam a garantir essa aparência e manutenção (visibilidade do corpo), passando a receber a mediação de múltiplos saberes e práticas dirigidas por "especialistas" (Borges, 2007). Observemos as seguintes afirmações:

“Eu consultei uma fonoaudióloga e ela disse que, esteticamente, por se tratar de uma passarela, ficar no alto e tal, seria mais bonito a S.A estar com os dentinhos e para dar entrevista também. Perfeito, coloca e tira. Aí eu consultei um dentista e o dentista disse 'Isso é tranquilo para fazer', até porque ela não vai permanecer com isso, só em alguns momentos (...) Então, assim, vai dar uma entrevista agora, coloca o dentinho. (...) vai desfilar, vai fotografar, coloca o dentinho." (A1)

Esta crescente busca pela preservação do vigor, da juventude, da beleza e aparência saudável tem sido incentivada pelos avanços tecnológicos ocorridos na medicina, biotecnologia, cosmética, dentre outros. Trata-se de modificar, alterar, corrigir, aperfeiçoar traços apenas para atender o desejo de adaptar o corpo aos arquétipos adequados e divulgados pela mídia. Ainda nessa perspectiva, Couto (2003) assinala que é divulgado a todo instante que cada um pode dispor das formas sonhadas, podendo modificar e compor a aparência desejada, reforçando e dinamizando o funcionamento do seu corpo. O autor ainda complementa elucidando que o corpo único, quase sempre cheio de defeitos e limitações, pode e deve ser substituído por múltiplas escolhas, pela versão anatômica adequada a cada ocasião ou performance que o indivíduo deseja. Com isso, cada parte do corpo pode ser trocada, refeita e reconfigurada, ou seja, "o corpo passa a ter uma estrutura modulável e as 'peças' envelhecidas, cansadas, doentes, podem ser substituídas, potencializadas" (Goellner, 2003, p. 177).
Essa ciência prevalecente no século XIX, que analisa e classifica o corpo, vai legitimando uma educação do corpo com o objetivo de torná-lo útil e produtivo, imprescindível para o trabalho nas indústrias em expansão e para o fortalecimento dos indivíduos visando à saúde e ao bem-estar. "Em nome da saúde e do bem-estar do indivíduo, o corpo passou a ser alvo de diferentes métodos disciplinares, entendido como um conjunto de saberes e poderes que investiram no corpo e nesse se instauraram..." visando à educação dos gestos, desvios sexuais, classificação das paixões, correção do corpo, por meio das atividades físicas, higiene e limpeza, por meio de banhos (Goellner, 2003, p. 35). Isso é evidenciado na fala da participante:

"Ela tem hábito de passar creme hipoalergênico no rosto quase que diariamente. No corpo, ela passa óleo hidratante no banho todos os dias, porque toma banho com água muito quente. O cabelo da S.A não tem cuidado muito específico. Usa um shampoo bom para cabelos com luzes e, eventualmente, vai ao salão fazer uma hidratação, cortar as pontinhas, alguma coisa assim. (...)A S.A. não é muito chegada em fritura." (A1)

Considerando-se as inúmeras possibilidades que se abrem para (re)significar os corpos neste contexto de concursos de beleza, podemos conhecê-las por meio da fala:

“(...) cílios, aplique, make e demais utilizados em concursos são todos normais e de fácil acesso no mercado nacional. São coisas que todas as meninas fazem uso e, inclusive, fora do Brasil elas são redobradas. O aplique é colocado com uma espécie de tic-tac, ou seja, prende e desprende do cabelo prontamente, após o uso. Os dentinhos são próteses provisórias, apenas para momentos de fotos ou entrevistas. E as maquiagens... essas são serviços contratados em cada lugar para onde se vai viajar. Normalmente, se leva um nécessaire com algum kit de make, mas por questões práticas, buscamos isso em salões especializados e bem capacitados." (A1) 
Essas representações vêm interpelando as crianças participantes de concurso de beleza, uma vez que "agregam nos seus corpos marcas que funcionam como códigos identitários que permitem reconhecer seu pertencimento a um determinado grupo cultural" (Louro, 2000, p. 71). Baseando-se nessas premissas, entende-se que o corpo infantil, em especial o das crianças participantes de concurso de beleza, precisa ser constantemente melhorado, ampliado, ajustado, modificado e até mesmo criado. Precisa-se de próteses e procedimentos de toda a ordem que as tornem belas e adequadas ao cenário das passarelas. O corpo parece ser um molde que se adapta às significações corporais.

Enquanto podemos observar uma preocupação histórica, particularmente moderna, de prevenção à feiura, a tônica hoje parece ser não somente corrigir as "imperfeições" que aparecem com o avançar da idade, mas prevenir o seu surgimento. Cada vez mais cedo se lança mão das mais diversas técnicas para se manter bela e/ou adquirir a forma física adequada.

\section{Considerações finais}

A partir deste estudo, observou-se que, atrelada à criança e sua participação nos concursos de beleza infantil, as pedagogias culturais assumem grande centralidade na produção de sua subjetividade e exerce um poder sobre ela ao produzir saberes sobre o seu corpo. Esses artefatos que estão imbricados na vida cotidiana da criança proclamam a necessidade de que a menina siga a "normalidade" posta pela mídia, inscrevendo no corpo determinados sinais de embelezamento e traçando os padrões que esta deve apresentar e mostrar.

Assim, como os(as) personagens vitoriosas(os) e personalidades famosas, a criança estudada, após se tornar mais visível por meio da mídia, passa a se constituir como ideal de corpo, gênero e sexualidade a ser seguido por outras crianças. Ela, desde muito cedo, é estimulada por essas pedagogias, seja por intermédio da mídia ou das pessoas envolvidas em seu contexto proximal, com o propósito de obter o corpo ideal. Após atingir esse ideal por meio dos concursos de beleza, acaba sendo referência aos demais infantis, traduzindo-se em uma espécie de "teia", uma vez que enreda e captura mais e mais crianças.

Para a manutenção desse ideal, a criança estudada busca estratégias que são propagadas na mídia como "passos" para alcançar a beleza almejada, tais como o uso de cosméticos diariamente, de roupas e acessórios que acompanham a moda e uma alimentação que mantenha o corpo com a aparência de magra. Nesse processo "de se parecer magra", cabe também a utilização de medicamentos que contribuem para que o corpo infantil se mantenha sempre "esbelto", preparado para todos os eventos, sejam eles relacionados à mídia ou não. Além disso, a tecnociência foi outra estratégia mencionada para compor o embelezamento da criança, utilizando-se como tática uma prótese dentária e, atrelado a isso, nota-se o investimento das ciências da saúde nessa composição para o aprimoramento do corpo para a questão do embelezamento dos corpos. Tudo isso para equipar a infraestrutura do corpo com o propósito de deixá-lo mais eficiente, produtivo, saudável, "válido" e visível, operando de forma performática nas passarelas.

O corpo, descoberto como "ferramenta utilitária" pelos meios de comunicação, vem sendo objeto de uma incansável interrogação que se estende dos outdoors às salas de cinema, dos jornais às passarelas dos concursos de beleza. De fato, o mundo globalizado parece ter colocado o corpo na ordem do dia. Por isso, os quesitos corpo, gênero e sexualidade exigem reflexão, cujo ponto de partida é dado pela ideia de que as pedagogias 
culturais "apropriam-se" do corpo biológico, por intermédio de discursos pedagógicos, para redefini-lo e, assim, transformá-lo em "espetáculo". Frente à atual sociedade, na qual o espetáculo se faz presente pelas mediações das imagens, os concursos de beleza infantil representam o corpo que está ali para ser visto, admirado e aplaudido.

Vale destacar que a criança utiliza-se de recursos da informatização que chama atenção para si por meio de filmagens que são divulgadas em redes sociais, o que leva a uma reflexão ainda no sentido da espetacularização desses corpos. As diferentes dimensões do "eu" na Internet são pensadas como "alterdirigidas". As experiências de subjetividade nas quais as dimensões "íntimas" e "confessionais" produzem construções de si orientadas para uma exposição que objetiva legitimar formas de ser e estar no mundo (Sibilia, 2008).

Em função disso, o corpo enquanto mercadoria assume a cena. A criança estudada se tornou divulgadora de produtos, assim como consumidora destes. As empresas investem nessa menina, atingindo suas expectativas e estimulando o consumo de produtos voltados especificamente para o público infantil. Além disso, o corpo dessa criança volta-se para a propaganda, seja de uma loja ou evento publicitário, assumindo a posição de corpo-mercadoria, ou seja, o corpo projetado para o consumo.

Não obstante, as possibilidades de experimentações que vêm sendo oferecidas à criança estão dentro de uma rede social mais ampla, da qual ela participa, não apenas como ouvintes dos discursos adultos sobre corpo, gênero e sexualidade. Defende-se, a partir desta, que além das interpelações de pessoas que vivem em seu ambiente proximal, também estão as alocações midiáticas que permeiam seu cotidiano. Esses discursos ensinam com eficiência, formando sujeitos, engendrando estilos e modos de ser, não se delimitando a uma determinada faixa etária. Assim, conduz ao favorecimento da "adultização" da criança, uma vez que ela se preocupa cada vez mais cedo com as questões do embelezamento, utilizando-se de recursos para a sua manutenção e aprimoramento da imagem corporal. Por fim, vale questionar qual infância estamos produzindo na contemporaneidade, principalmente de meninas, e de que forma ela tem sido instigada a conceber seus corpos perante os preceitos mercadológicos de embelezamento. 


\section{Isis Alves de Carvalho}

Graduada em Psicologia pelo Centro Universitário Franciscano, Santa Maria - RS. Brasil. E-mail: isisac_13@hotmail.com

\section{Monise Gomes Serpa}

Mestre em Psicologia pela Universidade Federal do Rio Grande do Sul, Porto Alegre RS. Brasil. Docente do Centro Universitário Franciscano, Santa Maria - RS. Brasil.

\section{Endereço para envio de correspondência:}

Centro Universitário Franciscano, Curso de Psicologia. R. Andradas. Centro. CEP: 97010-032 - Santa Maria, RS - Brasil

Recebido 05/06/2013, Aprovado 08/10/2013 
Borges, E. M. (2007). Corpo, espetáculo e consumo: novas configurações midiáticas para a infância. Media \& Jornalismo, 11(11), 91-103.

Castro, A. L. (2003). Culto ao corpo e sociedade: mídia, estilos de vida e cultura de consumo. São Paulo: Annablume.

Couto, E. S. (2003). Corpos modificados: o saudável e o doente na cibercultura. In G. L. Louro, J. F. Neckel, \& S. V. Goellner (Orgs.), Corpo, gênero e sexualidade: um debate contemporâneo na educação (pp. 172-185). Petrópolis, RJ: Vozes.

Debord, G. (1997). A Sociedade do Espetáculo: comentários sobre a sociedade do espetáculo. Rio de Janeiro: Contraponto.

Fischer, R. M. B. (2008). Pequena Miss Sunshine: para além de uma subjetividade exterior. PróPosições, 19(2), 47-57.

Foucault, M. (2004). Vigiar e punir. Petrópolis, RJ: Vozes.

Gil. A. C. (2009). Métodos e técnicas de pesquisa social. São Paulo: Atlas.

Goellner, S. V. (2003). A produção cultural do corpo. In G. L. Lourco, J. Felipe, \& S. V. Goellner (Org.), Corpo, gênero e sexualidade: um debate contemporâneo na educação (pp. 28-40). Petrópolis, RJ: Vozes.

Guizzo, B. S. (2010). "Aquele negrão me chamou de leitão": representações e práticas corporais de embelezamento na educação infantil. Dissertação de Doutorado, Programa de Pósgraduação em Educação, Universidade Federal do Rio Grande do Sul, Porto Alegre, RS.

Kellner, D. (2001). Beavis and Butt-Head: sem futuro para a juventude pós-moderna. In S. Steinberg, \& J. Kincheloe (Orgs.), Cultura infantil: a construção corporativa da infância (pp. 133159). Rio de Janeiro: Civilização Brasileira.

Kincheloe, J. (2001). Esqueceram de mim e Bad to the bone: o advento da infância pós-moderna. In S. Steinberg, \& J. Kincheloe (Orgs.), Cultura infantil: a construção corporativa da infância (pp. 53-86). Rio de Janeiro: Civilização Brasileira.
Louro, G. L. (2000). Currículo, gênero e sexualidade. Lisboa: Porto Editora.

Minayo, M. C. S. (1996) Desafio do conhecimento: pesquisa qualitativa em saúde. Rio de Janeiro: Hucitec.

Minayo, M. C. S. (2007). Pesquisa social: teoria, método e criatividade. Petrópolis, RJ: Vozes.

Neckel, J., \& Guizzo, B. S. (2003). Erotização dos corpos infantis na sociedade de consumo. Pro-Posições. 14 (3), 119-130.

Neckel, J. (2006). Representações de gênero, sexualidade e corpo na mídia. Revista Tecnologia e Sociedade, 3, 251-263.

Nechel, J., \& Goellner, S. V. (2005). Corpo, gênero e sexualidade: um debate contemporâneo na educação. Petrópolis, RJ: Vozes.

Queiroz, R. S., \& Otta, E. (2000). A beleza em foco: condicionantes culturais e psicobiológicos na definição da estética corporal. In R. S. Queiroz (Org.), O corpo do brasileiro: estudos de estética e beleza. São Paulo: Senac.

Sabat, Ruth. (2001). Pedagogia cultural, gênero e sexualidade. Revista Estudos Feministas, 9 (1), 04-21. doi: 10.1590/S0104026X2001000100002

Sibilia, P. (2008). O show do eu: A intimidade como espetáculo. São Paulo: Nova Fronteira.

Strenberg, S. (1997). Kindercultura: A construção da infância pelas grandes corporações. In L. H. Silva, J. C. Azevedo, \& E. Santos. Identidade social e a construção do conhecimento (pp. 98-145). Porto Alegre, RS: Ed. SMED.

Walkerdine, V. (1999). A cultura popular e a erotização das garotinhas. Educação \& Realidade, 24(2), 75-88.

Yin, R. (2005). Estudo de caso: planejamento e métodos. Porto Alegre, RS: Bookman. 